INTERVENTIONAL CARDIOLOGY AND SURGERY

\title{
Trends in coronary artery revascularisation procedures in Western Australia, 1980-2001
}

\author{
M S T Hobbs, K A McCaul, M W Knuiman, J M Rankin, I Gilfillan
}

Heart 2004;90:1036-1041. doi: 10.1136/hrt.2003.022160

\begin{abstract}
See end of article for authors' affiliations

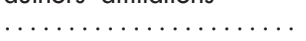

Correspondence to: A/Prof M S T Hobbs, School of Population Health, University of Western Australia, 35 Stirling Highway, Crawley WA 6009, Australia; mikeh@sph.uwa.edu.au
\end{abstract}

Accepted 28 November 2003

\begin{abstract}
Objectives: To describe trends in the use of coronary artery revascularisation procedures (CARPs) and to determine whether or when CARP rates will stabilise.

Setting: State of Western Australia.

Patients: All patients treated by coronary artery bypass grafting (CABG) or percutaneous coronary intervention (PCI) between 1980 and 2001.

Design: Descriptive study.

Main outcome measures: Age standardised rates of first and total CARPs, CABGs, and PCls.

Results: Overall rates for both total and first CARPs among men and women rose steeply from 1980 to 1993, when they abruptly stabilised or actually started to decline. Rates in age groups under 65 years tended to rise earlier in the period and remained relatively flat, while rates for people over the age of 75 years started to rise later and were still increasing at the end of the study.

Conclusions: Despite continuing increases in capacity to perform both CABG and PCl in Western Australia and evidence of continuing increases in the use of CARPs in the elderly population, rates appear to have stabilised for the first time since they were introduced.
\end{abstract}

$\mathrm{T}$ he development of coronary artery revascularisation procedures (CARPs), initially with coronary artery bypass grafting (CABG), then percutaneous coronary intervention (PCI), has greatly changed the management of ischaemic heart disease. Further impetus has been provided with the development of coronary artery stenting that has widened the scope and effectiveness of PCI. ${ }^{1}$ Rates of both CABG and PCI procedures have increased rapidly since the 1980-93 period in the USA, ${ }^{1-5}$ Canada, ${ }^{6}$ and Australia. ${ }^{7-10}$

Despite their proven effectiveness in reducing both mortality and morbidity from ischaemic heart disease, ${ }^{11-13}$ CARPs are costly in terms of resources. ${ }^{14}$ With declining incidence and mortality from ischaemic heart disease in Australia and New Zealand ${ }^{15}$ and other developed countries, ${ }^{16}$ the question of whether, or when, CARP rates will stabilise has become an important issue for policy makers but there is little agreement about this in the literature. ${ }^{17}{ }^{18}$ The question is complex because of the several factors that determine the need not only for primary procedures but also for revision procedures, particularly in the case of PCI, in which repeat procedures have accounted for up to $30 \%$ of all procedures. ${ }^{13}{ }^{19}$ Requirements for primary procedures are affected by trends in incidence and prevalence of ischaemic heart disease, changing clinical indications for revascularisation, and the effectiveness of alternative medical treatment. Revision procedures on the other hand are determined by the prevalence of previous CARPs and technical innovations that reduce the likelihood of restenosis. To understand the problem, we therefore need to distinguish between trends in primary and trends in revision procedures. We have been unable to find reports of such trends in the literature, possibly because record linkage that is necessary for the generation of person based data is not available in most jurisdictions.

In Western Australia, statewide health statistical data are routinely linked through the inclusion of personal identifying information. ${ }^{20}$ The Western Australian Health Data Linkage System holds records of all hospital separations in the state since 1980 and thus spans virtually the whole period of the uptake of CARPs. The purpose of this paper is to report on trends in total and first procedures, having particular regard to changing methods of revascularisation.

\section{METHODS}

\section{Setting}

Western Australia is the largest of the six states of Australia but accounts for only $10 \%$ of the total population of 18 million. All major medical services are concentrated in the capital city, Perth, which has a population of 1.3 million. Provision of medical treatment outside the state for any reason is rare. Facilities for the provision of CARP procedures increased from one hospital providing both CABG and PCI procedures in 1980 to four hospitals performing CABG procedures and seven hospitals performing PCI procedures in 1999. During that time the adult population 35 years and over increased by about $80 \%$.

\section{Data sources}

The study is based on a subset of records extracted from the Western Australian Health Data Linkage System containing electronic records of all hospital admissions or deaths from any form of cardiovascular disease occurring in the period 1979-2001 inclusive. Each record in the file contains a unique personal identifying number enabling the aggregation of records relating to individual patients. The file contained records for 423922 patients who had a diagnosis of cardiovascular disease coded in any of 17 diagnostic fields or a code for a cardiovascular procedure in any of 12 procedure fields. The total number of hospital admissions relating to these people (for any cause) was 3771819 and the total number of deaths was 130294.

Abbreviations: $C A B G$, coronary artery bypass grafting; CARPs, coronary artery revascularisation procedures; ICD, International classification of diseases; ICD-9-CM, International classification of diseases, ninth revision, clinical modification; $\mathrm{PCl}$, percutaneous coronary intervention 


\section{Definitions and ICD codes for CABG and PCI procedures}

"Percutaneous coronary intervention" is used throughout as a general term for all CARPs including percutaneous coronary transluminal angioplasty, coronary atherectomy, and coronary artery dilatation or stenting.

For the period 1979-87, procedures were coded using the International classification of procedures in medicine (ICPIM). ${ }^{21}$ The relevant codes for CABG procedures were 5-361 and 5-362 and for PTCA procedures, 5-363. From 1988 to mid 1999 , procedures were coded using the procedure classification associated with the International classification of diseases 9 th revision clinical modification (ICD-9-CM), ${ }^{22}$ (or from mid 1996, the second edition of the Australian versions of the above). During this period the relevant codes were 36.10-36.19 for CABG, 36.01-36.05 for PTCA, and 36.06 and 36.07 for PTCA with stents. From mid 1999, the Australian classification of health interventions ${ }^{23}$ was used with the codes being mapped to the ICD-9-CM codes described above.

\section{Identification of total and first CARPs}

For each admission record, all procedure codes were scanned and the record was flagged if it contained procedure codes corresponding to $\mathrm{CABG}$, PCI, or coronary stenting procedures. If both CABG and PCI were performed during the same admission, it was assumed that the PCI had failed and the case was classified as CABG. The records were then sorted by personal identifying number and dates of hospital admission. For each person the first record appearing with a CARP flag was marked as the first CARP for that person, irrespective of the type of procedure performed.

\section{Statistical methods}

For each year during the period 1980-2001, age standardised rates (with age broken into five year age groups) of all CABG, PCI, and all CARPs (CABG and PCI combined) were calculated for men and women for total and first procedures. Age standardisation was by the direct method with the 1996 Western Australian population distribution used as the standard. In addition, age specific rates of performance of CARPs, CABGs, and PCIs were calculated for age groups 3554 years, 55-64 years, 65-74 years, and 75 years or more. Annual mid-year estimates of the Western Australian population were obtained from the Australian Bureau of Statistics. ${ }^{24}$

\section{RESULTS}

Figure 1 shows age standardised rates of first and total procedures for CABG, PCI, and CARPs for men and women.

CABG procedures have been performed in Western Australia since the early 1970s but the rates were quite low until 1978, after which they increased rapidly. Thus, in fig 1, which starts in 1980, the rates for first procedures begin in the middle of this increase. Rates for first CABG then peaked in 1982-3, declined steadily until 1986, and rose steadily to peak again in 1992-3 before falling steadily until 2001. PCI procedures were introduced in 1980 and first PCI rates rose steadily until 2000 and decreased slightly in 2001. First PCI rates crossed over first CABG rates in 1997. Coronary artery stents were introduced in 1995 (vertical line in graph) and by 1999 were used in over 90\% of PCI procedures. First CARP rates rose steadily until 1993, when they stabilised for women and generally declined very slowly for men. Irregularities in trends are caused principally by fluctuations in CABG rates. CABG procedures declined from almost $100 \%$ of all CARPs in 1980 to about $60 \%$ in $1986-93$, then declined steadily to less than $40 \%$ in 2001 .

The pattern of trends for total CARPs (first and repeat procedures combined) was similar but their rate rose more steeply than for first procedures from 1980 until 1993, when they stabilised for women and generally declined very slowly for men. Also, the rates of total PCI overtook those for CABG somewhat earlier (in 1993-4) than the crossover for first procedures.

\section{Repeat procedures}

Figure 2 shows trends in the percentage of each of CABG, PCI, and CARPs that were repeat procedures in each year. In the case of all CARPs, this rose steadily from less than 5\% in 1980 to $29 \%$ for men and 25\% for women in 1995 before declining to $24 \%$ and $21 \%$, respectively, in 2001 . The patterns were very different for PCI and CABG. Repeat PCI as a percentage of all PCI procedures peaked at $38 \%$ for men and $35 \%$ for women and had the greatest decline (to $32 \%$ and $24 \%$, respectively, in 2001). Repeat CABG peaked earlier at $20 \%$ for men and $16 \%$ for women before falling to $14 \%$ and $18 \%$, respectively. It must be emphasised that repeat CARPs, whether CABG or PCI, were not necessarily for the same type of procedure and do not indicate the risk of repeat procedures in each procedure type, as no account is taken of years of follow up. For example, over the whole period of the study, $12.5 \%$ of first CABG procedures were followed by repeat procedures of which only $45.4 \%$ were CABG. In contrast, $42.9 \%$ of first PCI procedures were followed by repeat procedures of which $75.3 \%$ were PCI. The estimation of the true risk of repeat procedures after either CABG or PCI and how this may have changed over time can only be determined by survival analysis. This is examined in a separate paper. ${ }^{25}$

\section{Age specific trends in first procedures}

Figure 3 shows age and sex specific trends in first CARPs, CABG, and PCI rates. In general, rates in younger age groups rose earlier and stabilised or fell earlier than in older age groups. For example, in 1980 the rates of CARPs for men were highest in those aged 55-64 years but, although these rates continued to rise, they were overtaken in 1989 by rates for men aged $65-74$ years. Rates in the three youngest age groups stabilised or began to fall in 1993. In contrast, rates for patients 75 years and over were initially lower than those in other age groups and rose relatively slowly until 1988. They then increased rapidly to be second only to rates for men aged 65-74 years by the end of the study. For women similar patterns were observed but declines in rates in later years were more obvious in those aged 55-64 year and 65-74 years.

In the case of $C A B G$, rates for both men and women aged 35-54 and 55-64 years reached their peak early in the study then gradually declined. In contrast, rates for patients aged 65-74 years rose steeply until 1993 then fell equally steeply, while rates for those 75 years and over rose relatively late and then stabilised around 1993. Rates of PCI for men rose equally in the three youngest age groups but in men aged 75 years and over, rates rose slowly at first before rising rapidly to almost overtake those in all other age groups. For women the pattern was similar except that rates in the two youngest age groups stabilised after 1993.

\section{DISCUSSION}

After rising continuously from 1980 to 1993, rates of CARPs in Western Australia stabilised for both men and women. This overall pattern, however, tended to obscure differences in age specific trends, with early uptake of procedures and early stabilisation of rates being related inversely to age. These differences are consistent with the long term decline in the epidemic of coronary heart disease in Australia, which began at the end of the 1960s and was initially more pronounced in younger age groups. ${ }^{26}$ The later rapid increase in rates in the elderly, however, suggests that other factors, 

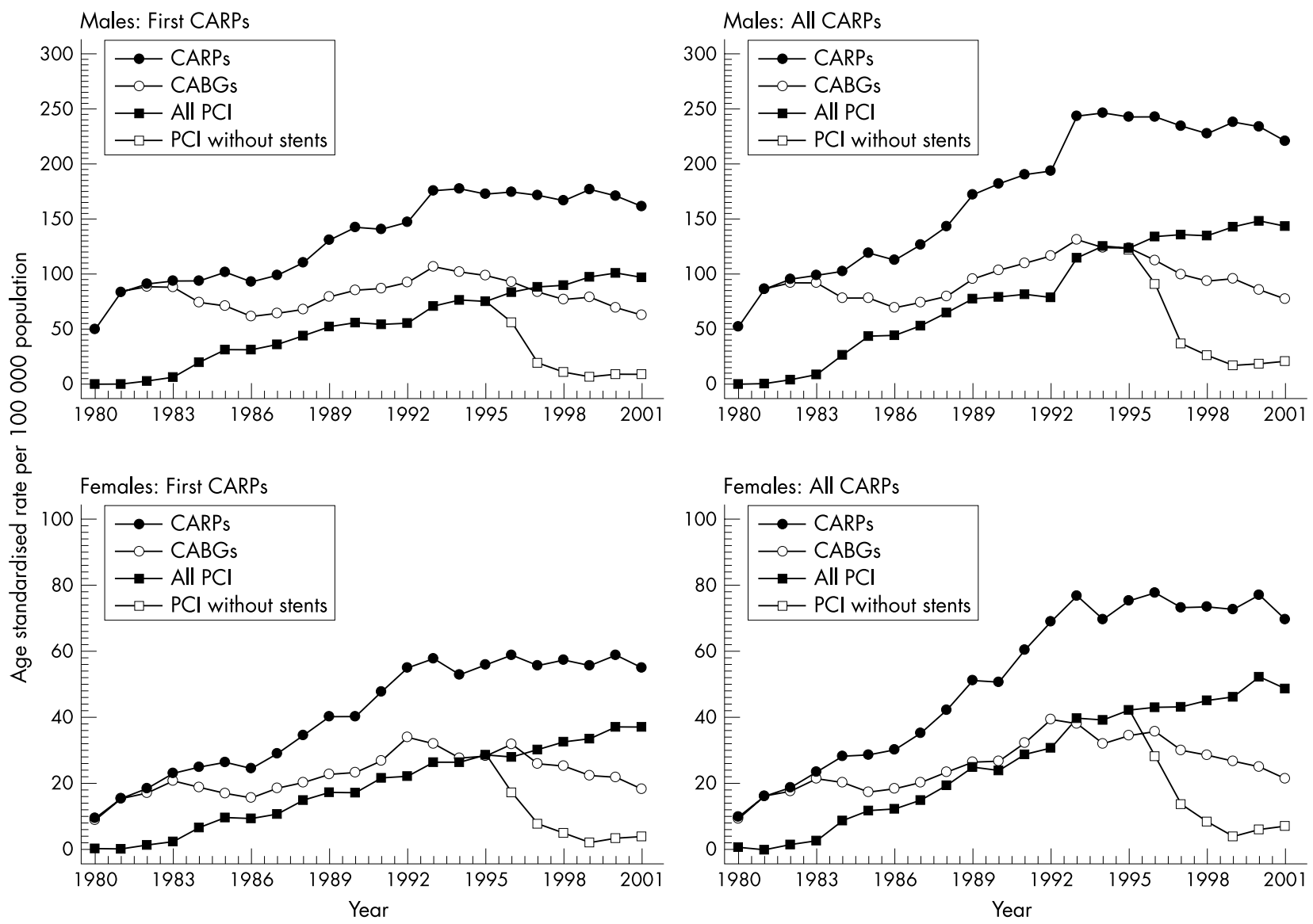

Figure 1 Age standardised rates of first and total coronary artery revascularisation procedures (CARPs) for men and women in Western Australia, 1980-2001. CABG, coronary artery bypass graft; all PCl, all percutaneous coronary interventions; PCl without stents, $\mathrm{PCl}$ s without the use of coronary stents.

including changes in clinical attitudes and indications for CARPs, were operating. For example, among patients admitted to hospital for acute myocardial infarction during the study period, the probability of undergoing a CARP within one year of the acute myocardial infarction was also inversely related to age, ${ }^{27}$ suggesting that in the past younger patients were treated more intensively. Similar trends in the age distribution of patients receiving CARPs have been reported in other countries. ${ }^{29-31} \mathrm{~A}$ substantial decline in overall procedure rates would therefore not be expected until this trend towards increasing revascularisation among the elderly finally levels out.

During the period of the study, there was a continuous increase in PCI rates, whereas rates of CABG fluctuated before peaking in 1992-3 then falling steeply. There seems little doubt that fluctuations in CABG rates have been at least partly caused by substitution of PCI for CABG, first when PCI rates began to increase between 1980 and 1986 and again after the introduction of coronary artery stents in 1995. Substitution of PCI for CABG, principally for
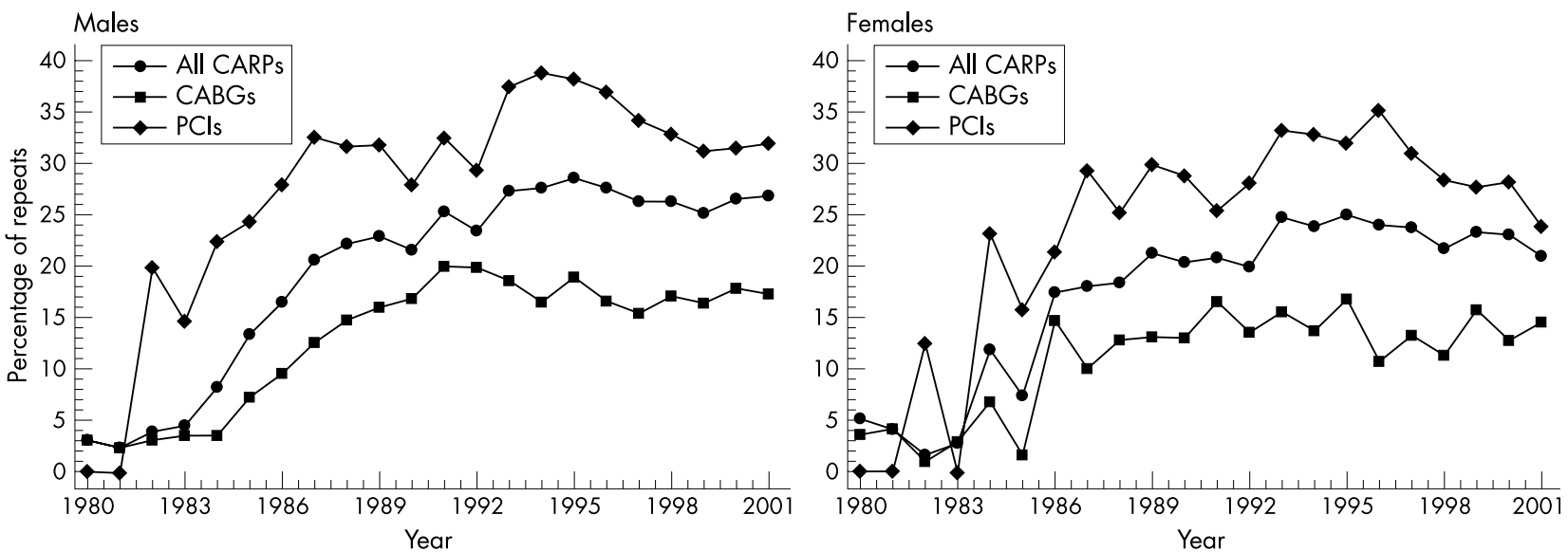

Figure 2 Trends in the percentage of total CARP, CABGs, and PCls that were repeat procedures. 

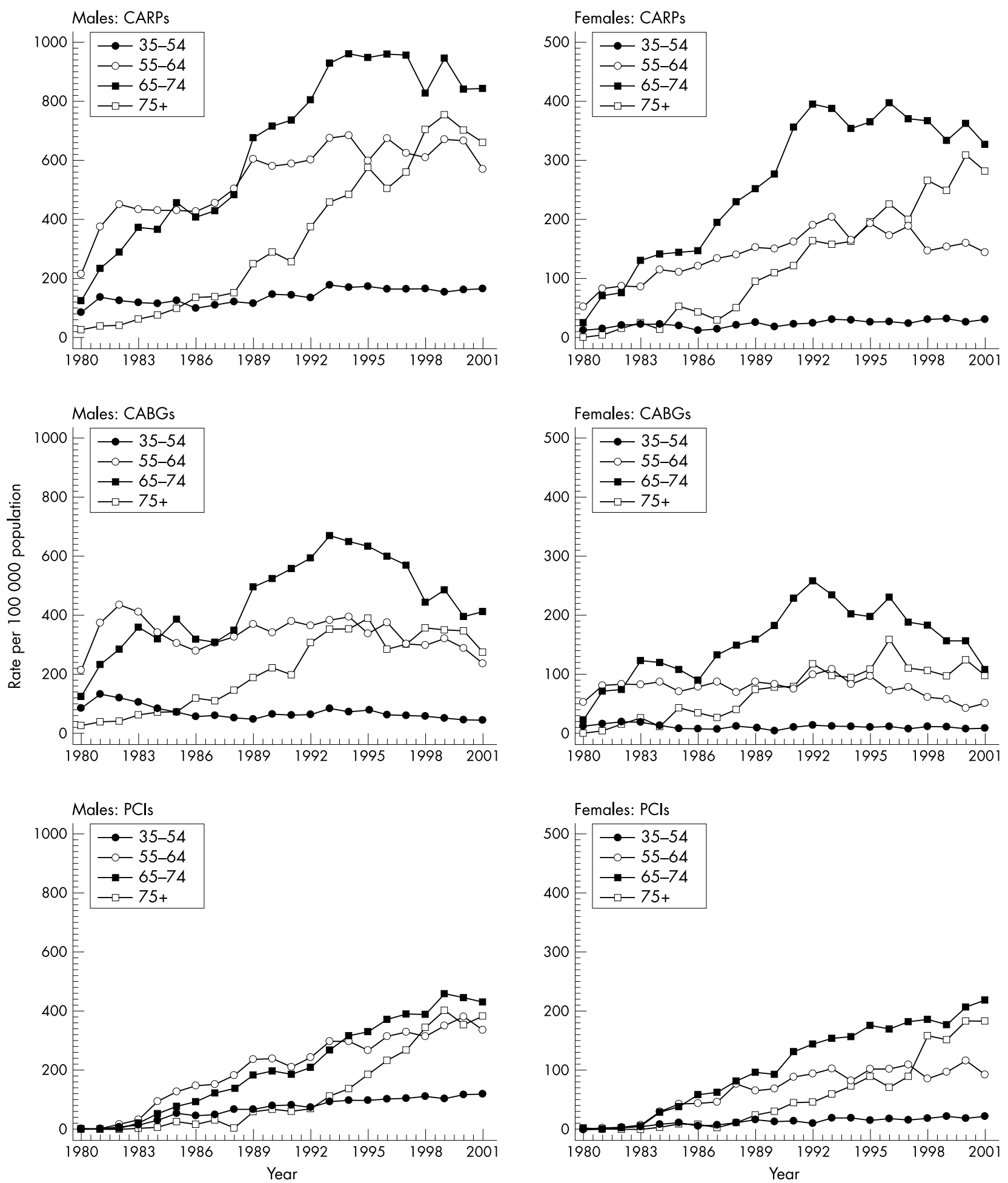

Figure 3 Age standardised rates for first CARPs, CABGs, and PCls for men and women in Western Australia by age group, $1980-2001$.

single vessel revascularisation, has been reported in other studies. ${ }^{13}{ }^{32}$ Since the advent of stents there is also evidence of increased use of PCI in the treatment of acute coronary syndromes in which CABG would not usually be considered as the first option. ${ }^{1272833-35}$ National data from the USA since 1990 indicate that rates for CABG continued to rise steeply until 1992 before levelling off and then declining after 1997. Rates for PCI on the other hand rose steeply from 1995 until 1999 before declining in 2000. During this time PCI, which initially accounted for less than half of total procedures, increased to about two thirds of total procedures. $^{5}$

The reasons for the temporary resurgence of CABG after 1986 are unknown but this may have been influenced by publication in that year of the landmark study of Loop and colleagues $^{36}$ showing significantly improved 10 year survival after such procedures that involved internal mammary artery grafts. Unfortunately, we are unsure of the accuracy of 
coding of internal mammary artery grafts in our data until before 1990, by when they were used in about $80 \%$ of cases.

Rates of repeat procedures as a proportion of all procedures rose until 1993 then gradually fell. The initial increase was due to a combination of a higher percentage of repeat procedures in PCI than in CABG and the increasing proportion of primary procedures in which PCI was performed. The subsequent decline in repeat procedures may have been at least partly caused by a rapid increase in the use of coronary artery stents from 1995, a finding that is consistent with other descriptive studies and clinical trials. ${ }^{12378}$ In our data, however, it was not possible to distinguish between repeat procedure performed because of restenosis and procedures undertaken as part of either planned multistage treatment or because of progression of disease in other vessels. Resolution of the role of stents in the decline of repeat procedures will require more precise identification of procedures related to restenosis at the site of previous revascularisation, which we are undertaking as part of a further study.

Improved medical treatment of patients with coronary heart disease may also have tempered the demand for CARPs since 1993. Randomised clinical trials of lipid lowering drugs and angiotensin converting enzyme inhibitors after acute myocardial infarction or for patients with subacute coronary heart disease have both shown reduced CARP rates. ${ }^{39}{ }^{40}$ In Perth, the proportion of patients with acute myocardial infarction prescribed lipid lowering agents and angiotensin converting enzyme inhibitors at discharge increased from $8 \%$ and $29 \%$, respectively, in 1993 to $62 \%$ and $48 \%$, respectively, in $1998 .{ }^{41}$

Our study, which was based on routinely collected administrative data, has a number of limitations. Although some of the irregularities in the initial rise in rates up to 1993 were almost certainly related to incremental increases in capacity in the form of new units performing CARPs (see Methods), artefact caused by changes in disease coding classifications (table 1) or changes in local coding practices is also possible. The most important of these were the introduction in 1988 of the ICD-9-CM and associated procedure codes and the further revision of ICD-9-CM in July 1996. These changes were most likely to have affected the coding of PCI, which progressed though a number of steps during the study period, but no obvious discontinuities in PCI trends between 1987 and 1988 or between 1995 and 1996 were seen. No information is available about the accuracy or consistency of coding of CARPs, but both are likely to have improved as the result of major increases in resources allocated for disease coding in hospitals in the early 1990s to support the development of case-mix funding of public hospitals. As the most probable effect of this would be an apparent increase in procedure rates, we believe that the decline in rates after 1993 is real.

A further issue is the validity of our attempt to identify first CARPs. Through record linkage we identified the first CARP received by each patient in the study period. In the case of

Table 1 ICD-9 and ICD-9-CM code definitions for $\mathrm{CABG}$ for $\mathrm{PCl}$

\begin{tabular}{lll}
\hline & ICD-9 & ICD-9-CM \\
\hline CABG & $5-361,5-362$ & $36.1-36.19$ \\
PCl & $5-363$ & $36.0-36.05$ \\
PCl with stenting & NA & $36.06,36.07$ \\
\hline
\end{tabular}

CABG, coronary artery bypass grafting; ICD-9, International classification of diseases, 9th revision; ICD-9-CM, International classification of diseases, 9th revision, clinical modification; NA, not applicable; $\mathrm{PCl}$, percutaneous coronary intervention.
PCI this is likely to be valid, as this procedure was not performed in Western Australia until 1980. On the other hand, CABG was introduced into Western Australia in 1976 and we may have slightly overestimated the number of first CABG procedures in the early years of the study. The rapid increase in the population of Western Australia during the study period, due largely to immigration, is a further potential source of error, as our data cannot identify patients who may have had their first CARP before settling in Western Australia. In a separate study, linkage of all cases of CABG performed in Western Australia until the end of 1993 to the national death index found very few deaths outside Western Australia, suggesting that migration of patients after CABG is uncommon. $^{42}$

\section{ACKNOWLEDGEMENTS}

We are grateful for help with the preparation of data files used for this study, which was provided by Mr Steve Ridout from the Unit of Clinical Epidemiology within the School of Population Health and by Ms Di Rosman and staff at the Data Linkage Unit. The Unit of Clinical Epidemiology is supported by a grant from the Western Australian Department of Health. This study was funded by the National Health and Medical Research Council (project grant number 139100).

\section{Authors' affiliations}

M S T Hobbs, K A McCaul, M W Knuiman, School of Population Health, University of Western Australia, Crawley, Western Australia, Australia J M Rankin, Department of Cardiology, Royal Perth Hospital, Perth, Western Australia

I Gilfillan, Cardiothoracic Surgery Unit, Fremantle Hospital, Fremantle, Western Australia

\section{REFERENCES}

1 Hasdai D, Berger PB, Bell MR, et al. The changing face of coronary interventional practice: the Mayo Clinic experience. Arch Intern Med 1997; 157:677-82.

2 Gillum RF. Coronary artery bypass surgery and coronary angiography in the United States, 1979-1983. Am Heart J 1987;113:1255-60.

3 Feinleib M, Havlik RJ, Gillum RF, et al. Coronary heart disease and related procedures: national hospital discharge survey data. Circulation 1989;79:113-8

4 Gillum RF, Gillum BS, Francis CK. Coronary revascularization and cardiac catheterization in the United States: trends in racial differences. J Am Coll Cardiol 1997; 29: 1557-62.

5 Anon. National Center for Health Statistics. Vital and health statistics, series 13: national hospital discharge survey: annual summary, 1987-2000. Hyattsville: US Department of Health and Human Services, 2002.

6 Ugnat AM, Naylor CD. Trends in coronary artery bypass grafting in Ontario from 1981 to 1989. Can Med Assoc J 1993;148:569-75.

7 Davies J, Senes S. Coronary angioplasty 1998. Canberra: AlHW and National Heart Foundation, 2001.

8 Davies J, Senes S. Cardiac surgery in Australia 1998. Canberra: AlHW and National Heart Foundation of Australia, 2001.

9 Davies J, Senes S. Coronary angioplasty 1999. Canberra: AlHW and National Heart Foundation of Australia, 2002

10 Senes S, Davies J. Coronary angioplasty in Australia 1996. Canberra: AlHW and National Heart Foundation, 1999.

11 Yusuf S, Zucker D, Peduzzi $P$, et al. Effect of coronary artery bypass graft surgery on survival: overview of 10-year results from randomised trials by the coronary artery bypass graft surgery trialists collaboration. Lancet 1994;344:563-70

12 Serruys PW, de Jaegere $P$, Kiemeneij F, et al. A comparison of balloonexpandable-stent implantation with balloon angioplasty in patients with coronary artery disease. BENESTENT study group. N Engl J Med 1994;331:489-95

13 The Bypass Angioplasty Revascularization Investigation (BARI) Investigators. Comparison of coronary bypass surgery with angioplasty in patients with Comparison of coronary bypass surgery with angiopla
multivessel disease. N Engl J Med 1996;335:217-25.

14 Waters A, Armstrong T, S-F. S. Medical care of cardiovascular disease in Australia. Canberra: Australian Institute of Health and Welfare, 1998.

15 Beaglehole R, Stewart AW, Jackson R, et al. Declining rates of coronary heart disease in New Zealand and Australia, 1983-1993. Am J Epidemiol 1997; 145:707-13.

16 Tunstall-Pedoe H, Kuulasmaa K, Mahonen M, et al. Contribution of trends in survival and coronary-event rates to changes in coronary heart disease mortality: 10-year results from 37 WHO MONICA project populations. Monitoring trends and determinants in cardiovascular disease. Lancet 1999;353:1547-57. 
17 Dzavik V. The need for revascularization procedures will remain the same or increase in the next decade. Can J Cardiol 1998; 14(suppl A):27A-31A.

18 Kastrati A, Schomig A, Dietz R, et al. Time course of restenosis during the first year after emergency coronary stenting. Circulation 1993;87:1498-505.

19 Sim I, Gupta M, McDonald K, et al. A meta-analysis of randomized trials comparing coronary artery bypass grafting with percutaneous transluminal coronary angioplasty in multivessel coronary artery disease. Am J Cardiol 1995;76:1025-9.

20 Holman CD, Bass AJ, Rouse IL, et al. Population-based linkage of health records in Western Australia: development of a health services research linked database. Aust N Z J Public Health 1999;23:453-9.

21 World Health Organization. International classification of procedures in medicine. Geneva: WHO, 1978

22 Commission on Professional and Hospital Activities. International classification of diseases, 9th revision, clinical modification: ICD-9CM: vol 3. Procedures-tabular list and alphabetic index. Annoted ed. Ann Arbour, Michigan: Commission on Professional and Hospital Activities; 1987

23 National Centre for Classification in Health. International classification of diseases and related health problems, 10th revision, Australian modification (ICD-10-AM) vol 3. Tabular list of procedures ICD-10-AM. Australian classification of health interventions (ACHI). Sydney: National Centre for Classification in Health, 2002.

24 Australian Bureau of Statistics. Population by age and sex, Australian States and Territories, 2001. Canberra: Australian Bureau of Statistics. 2002. Catalogue No. 3201.0

25 McCaul KA, Hobbs MST, Knuiman MW, et al. Trends in two year risk of repeat revascularisation or death from cardiovascular disease after coronary artery bypass grafting or percutaneous coronary intervention in Western Australia, 1980-2001. Heart 2004:90:1042-6.

26 Mathur S. Epidemic of coronary heart disease and its treatment in Australia. Canberra: Australian Institute of Health and Welfare, 2002.

27 Hobbs MST, Bertuola B, Geelhoed E, et al. Changes in medical treatments and their consequences for patient health outcomes. In: McClellan M, Kessler D, eds. Technological change in health care: a global analysis of heart attack. Ann Arbor: University of Michigan Press, 2002.

28 McClelland MB, Every N, Garber PH, et al. Technological change in heart attack in the United States. In: McClellan M, Kessler D, eds. Technological change in health care: a global analysis of heart attack. Ann Arbor: University of Michigan Press, 2002

29 Disch DL, O'Connor GT, Birkmeyer JD, et al. Changes in patients undergoing coronary artery bypass grafting: 1987-1990. Northern New England cardiovascular disease study group. Ann Thorac Surg 1994;57:416-23.
30 Eggerstedt JM, Mancini MC. Current trends and considerations in the surgical treatment of coronary artery disease. J La State Med Soc 1995; 147:217-22.

31 Smith JM, Rath R, Feldman DJ, et al. Coronary artery bypass grafting in the elderly: changing trends and results. J Cardiovasc Surg (Torino) 1992:33:468-71

32 Weintraub WS, Jones EL, King SB, et al. Changing use of coronary angioplasty and coronary bypass surgery in the treatment of chronic coronary artery disease. Am J Cardiol 1990;65:183-8.

33 Grines $\mathrm{CL}, \mathrm{O}^{\prime} \mathrm{Neill}$ WW. Multivessel angioplasty versus bypass surgery: a case for PTCA. Eur Heart J 1995;16(suppl E):29-31.

34 GUSTO Ilb Investigators. A clinical trial comparing primary coronary angioplasty with tissue plasminogen activator for acute myocardial infarction. The global use of strategies to open occluded coronary arteries in acute coronary syndromes (GUSTO llb) angioplasty substudy investigators. N Engl J Med 1997;336:1621-8

35 Zijlstra F, Hoorntje JC, de Boer MJ, et al. Long-term benefit of primary angioplasty as compared with thrombolytic therapy for acute myocardial infarction. N Engl J Med 1999;341:1413-9.

36 Loop FD, Lytle BW, Cosgrove DM, et al. Influence of the internal-mammary artery graft on 10-year survival and other cardiac events. N Engl J Med 1986;314:1-6.

37 Fischman DL, Leon MB, Baim DS, et al. A randomized comparison of coronary-stent placement and balloon angioplasty in the treatment of coronary artery disease. Stent restenosis study investigators. N Engl J Med 1994;331:496-501.

38 Rankin JM, Spinelli JJ, Carere RG, et al. Improved clinical outcome after widespread use of coronary-artery stenting in Canada. N Engl J Med 1999;341:1957-65.

39 Sacks FM, Pfeffer MA, Moye LA, et al. The effect of pravastatin on coronary events after myocardial infarction in patients with average cholesterol levels. Cholesterol and recurrent events trial investigators. N Engl J Med 1996;335:1001-9

40 Yusuf S, Sleight $P$, Pogue J, et al. Effects of an angiotensin-converting-enzyme inhibitor, ramipril, on cardiovascular events in high-risk patients. The heart outcomes prevention evaluation study investigators. N Engl J Med 2000;342:145-53.

41 McElduff $P$, Dobson A, Jamrozik K, et al. The WHO MONICA study, Australia, 1984-1993: a summary of the Newcastle and Perth MONICA projects. Canberra: Australian Institute of Health and Welfare, 2000.

42 Bradshaw PJ, Jamrozik K, Jelfs P, et al. Mobile Australians: a moving target for epidemiologists. Med J Aust 2000;172:566.

\section{IMAGES IN CARDIOLOGY}

\section{Tuberculous pericardial abscess causing right ventricular obstruction}

A 33 year old Cabo Verdian woman presented with precordial chest pain and dizziness on exertion. Four months earlier she had successfully been treated because of systemic tuberculosis accompanied by ascites, pleural and pericardial effusion, and generalised lymphadenopathy. Physical examination showed a moderately ill patient with an elevated jugular venous pressure, a systolic murmur on the fourth left intercostal space, an enlarged liver, and pitting oedema on both legs. The ECG demonstrated sinus rhythm with normal intervals, voltages, and diffusely inverted $\mathrm{T}$ waves. Two dimensional echocardiography revealed a large extracardiac mass obstructing the free wall of the right ventricle (left panel). There was a moderate tricuspid insufficiency. Magnetic resonance imaging confirmed the echocardiographic findings, demonstrating a fluid containing mass of $5 \times 6 \mathrm{~cm}$ with a very thick wall causing severe cavity reduction of the right ventricle (right panel).

Subsequently thoracotomy was performed. An abscess with a thick wall was encountered with infiltration of the right ventricular wall. The abscess was
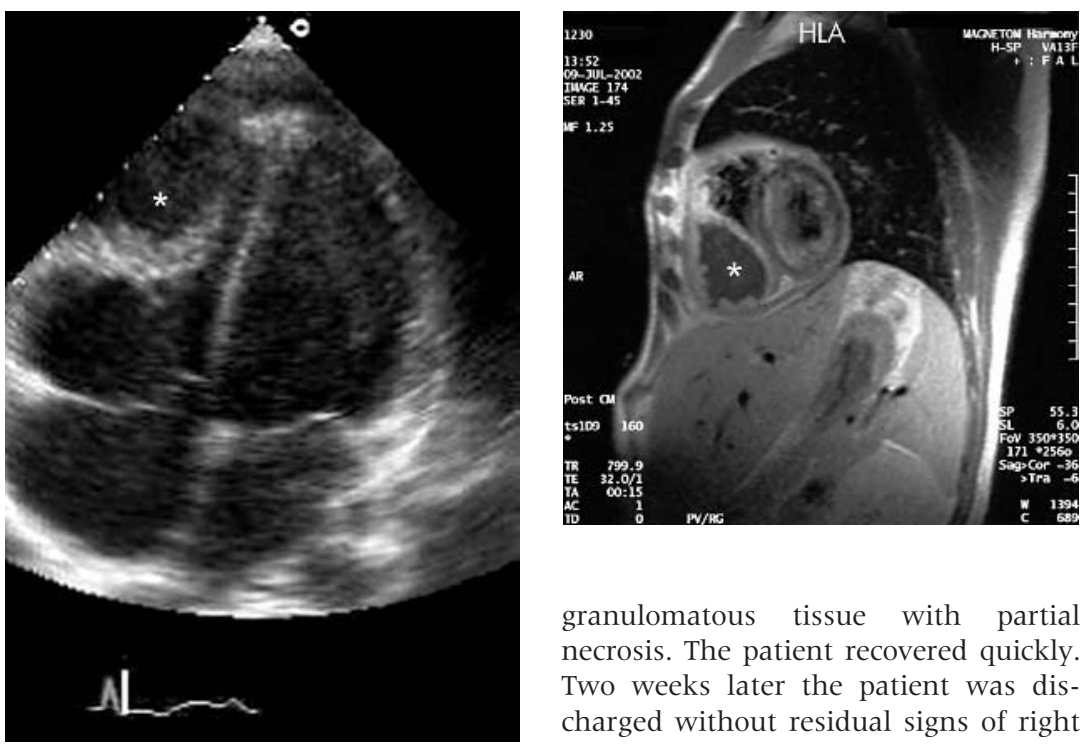

granulomatous tissue with partial necrosis. The patient recovered quickly. Two weeks later the patient was discharged without residual signs of right sided heart failure. No new mass has recurred so far. Only a moderate tricuspid regurgitation remained on echocardiography.

removed as much as possible. The "bottom" was left in place because of its continuation into the right ventricular wall. The fluid of the abscess was positive for acid-fast bacilli, confirming the diagnosis of a tuberculous abscess. Microscopic examination demonstrated
K Caliskan

T W Galema A P J Klootwiik

k.caliskan@erasmusmc.nl 